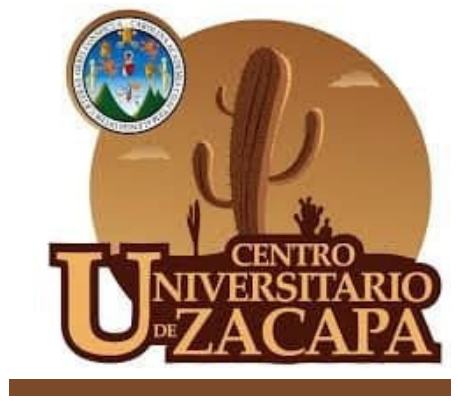

Recibido: 21/01/2021

Ensayo científico

Publicado: 24/05/2021

\title{
El bloque de constitucionalidad: la expansión de la Constitución dogmática
}

\section{The constitutionality bloc: the expansion of the dogmatic Cons- titution}

\author{
Julio César Cordón Aguilar \\ Universidad de San Carlos de Guatemala \\ jucordoncr@gmail.com \\ https://orcid.org/0000-0001-5408-0948
}

\section{Referencia del ensayo}

Cordón Aguilar, J. C. (2021). El bloque de constitucionalidad: la expansión de la Constitución dogmática. Revista Académica CUNZAC, 4(2). 39-47. DOI: https://doi.org/10.46780/cunzac.v4i2.42.

\section{Resumen}

El artículo 46 de la Constitución guatemalteca reconoció la preeminencia del derecho internacional de los derechos humanos sobre el derecho nacional. La Corte de Constitucionalidad, como intérprete máximo de la Constitución, se ha pronunciado sobre el contenido y alcances del citado precepto. En su jurisprudencia, la Corte ha sostenido dos criterios en torno al artículo 46 constitucional. En una primera época, que corresponde al periodo 1989-2011, el criterio imperante estuvo dominado por el concepto de jerarquía normativa, de forma que se tornaría invariable cuestionar siquiera el carácter supremo de la Constitución. Tal perspectiva, de base formalista, no logró evidenciar el sentido último del precepto bajo interpretación, en tanto puso el énfasis en la jerarquización de las normas, obviando la efectividad y tutela de los derechos humanos. La innovación jurisprudencial vendría en 2011 mediante la aplicación de la figura del bloque de constitucionalidad, de origen francés, con el que toda la discusión se enfocó en el interés por garantizar la máxima tutela de los derechos humanos, entendiendo que este habría sido el verdadero sentido del precepto constitucional. El criterio transformó la perspectiva de jerarquía por la de complementariedad, proveyendo una tutela amplia y expansiva de los derechos.

Palabras clave: constitución, derechos humanos, bloque de constitucionalidad, derecho internacional

\begin{abstract}
Article 46 of the Guatemalan Constitution recognized the preeminence of international human rights law over national law. The Constitutional Court, as the highest interpreter of the Constitution, has ruled on the content and scope of the aforementioned precept. In its jurisprudence, the Court has upheld two criteria regarding article 46 of the Constitution. In a first period, which corresponds to the period 1989-2011, the prevailing criterion was dominated by the concept of normative hierarchy, so that it would become invariable to even question the supreme character of the Constitution. Such a formalist-based perspective failed to reveal the ultimate meaning of the precept under interpretation, as it emphasized the hierarchy of norms, ignoring the effectiveness and protection of human rights. The jurisprudential innovation would come in 2011 through the application of the figure of the constitutionality block, of French origin, with which the entire discussion focused on the interest to guarantee the maximum protection of human rights, understanding that this would have been the true meaning of the constitutional precept. The criterion transformed the perspective of hierarchy into that of complementarity, providing a broad and expansive protection of rights.
\end{abstract}

Keywords: constitution, human rights, constitutionality block, international law

\begin{tabular}{l|l|l|l|l}
\hline CUNZAC & Revista del Centro Universitario de Zacapa & ISSN: 2708-7158 & Volumen 4 & Número 2 Julio - Diciembre 2021
\end{tabular}




\section{Introducción}

En la actualidad, la Constitución ha dejado de ser un mero instrumento político de organización del Estado y se ha convertido en un verdadero sistema de valores y principios que provee protección a la esfera de derechos y libertades de la persona, y que proclama el deber de respeto y garantía que, respecto de tales derechos y libertades, recae en la organización estatal. En línea con esa visión de tutela de los derechos humanos, la Constitución guatemalteca, vigente desde 1986, además de incorporar un amplio catálogo de libertades, pretendió incorporar al ámbito interno, por vía de su artículo 46 , toda la protección que los estándares internacionales pueden proveer.

De esa cuenta, como órgano encargado de la defensa del sistema de derechos, la Corte de Constitucionalidad ha debido interpretar el artículo en referencia. Así, sus criterios no siempre han respondido al interés por una protección amplia y efectiva de la persona, sino, más bien, a reafirmar el carácter fundamental y supremo de la propia Constitución.

Este trabajo intenta ofrecer una explicación sucinta de los criterios que la Corte ha expresado en torno al precepto del artículo 46 constitucional. Tales criterios han ido de una visión eminentemente formal, apoyada en el concepto de jerarquía normativa, a una perspectiva evolutiva que ha encontrado en la figura del bloque de constitucionalidad una herramienta perfecta para asegurar la coherencia del derecho interno y el derecho internacional, pero principalmente para garantizar la más amplia y efectiva protección de los derechos y libertades inherentes a la dignidad humana, en una especie de expansión del marco constitucional útil para su respeto y salvaguarda.

\section{Contenido}

El problema de fondo relativo a los derechos humanos no es hoy tanto el de justificarlos, como el de protegerlos (Bobbio, 1991).

\section{a) Constitución y derechos humanos}

La entrada en vigencia de la Constitución guatemalteca, el 14 de enero de 1986, significó una redefinición de la función del Estado, de la especial posición del ser humano en ese contexto y, en definitiva, de los valores y principios que inspiran a la organización social. En tal sentido, de manera totalmente novedosa para el sistema jurídico y político guatemalteco, la Constitución proclamó, desde su preámbulo, "la primacía de la persona humana como sujeto y fin del orden social".

Asimismo, el nuevo texto constitucional -que en enero de 2021 cumplió 35 años de vigencia- afirmó que la razón de ser del Estado es proveer protección "a la persona y a la familia" (artículo $1^{\circ}$ ), y que el fin de su organización es "garantizar a sus habitantes el goce de sus derechos y de sus libertades" (artículo 140) (Constitución Política de la República de Guatemala [CPRG]. 31 de mayo de 1985). Para el efecto, el propio marco constitucional, además de reconocer un amplio catálogo de derechos individuales y sociales, lo que se conoce como parte dogmática (Naranjo, 2003, p. 337), incorporó también en su estructura organizativa o parte orgánica distintas instituciones totalmente novedosas en el contexto nacional, a las que confió la garantía plena de los derechos y libertades fundamentales. De esa cuenta, entre otros órganos, la normativa constitucional incorporó al Tribunal Supremo Electoral como autoridad máxima en el ámbito político-electoral y en materia de derechos políticos, así como

Volumen 4 | Número 2| Julio-Diciembre 2021 
al Procurador de los Derechos Humanos en su papel de comisionado del Congreso de la República encargado de la defensa de los derechos humanos, y a la Corte de Constitucionalidad, órgano al que encomendó, como función esencial, defender el orden constitucional, con todo lo que tal concepto conlleva.

En efecto, esa tarea de "defensa del orden constitucional" (artículo 268 CPRG) determinó reconocer en un tribunal de justicia independiente de los demás poderes del Estado -lo que diferencia a la Corte nacional del resto de órganos análogos a nivel de Centroamérica y de varios Estados de América Latina (Helmke y Ríos, 2010, p. 64)- la función de interpretar, en calidad de instancia máxima, los preceptos y mandatos del texto constitucional. De esa cuenta, la "defensa del orden constitucional" conlleva no sólo la labor de controlar el actuar de los poderes públicos y su sujeción a la Constitución, sino una permanente tarea de interpretación del contenido de esta última, a fin de proyectar, en cada caso concreto, la eficacia de su texto, lo que supone, en sí mismo, defender y velar por el cumplimiento de sus mandatos.

Pues bien, el marco dogmático, es decir, el catálogo de derechos y libertades que la Constitución guatemalteca reconoce y exige garantizar, se termina de completar con dos preceptos de evidente amplitud $y$, por ende, de necesaria interpretación. El primero, el artículo 44 que, por un lado, reconoce plena validez y protección a aquellos derechos que, sin importar que "no figuren expresamente" en la Constitución, son inherentes a la dignidad humana. Por otro lado, el precepto sanciona con nulidad absoluta y de pleno derecho (ipso jure) cualquier disposición o normativa, de cualquier categoría, que disminuya, restrinja o tergiverse los derechos que la propia Constitución garantiza*.

Por su parte, el artículo 46 del texto constitucional incluyó una redacción totalmente novedosa en la historia jurídica interna, pero no por ello alejada de polémica, en tanto afirmó que los tratados y convenciones sobre derechos humanos, aceptados y ratificados por el Estado, "tienen preeminencia sobre el derecho interno". Así, el contenido y, especialmente, los alcances de esta norma han configurado temas de permanente debate, lo que ha provocado que la Corte de Constitucionalidad haya debido pronunciarse en más de una ocasión sobre la interpretación que se impone a partir del texto del artículo citado*. Sin perjuicio de que en las líneas que prosiguen se intentará hacer una breve explicación de los sentidos que el tribunal constitucional ha deducido de dicho texto, cabría adelantar que la diferencia de criterios ha estribado en las distintas perspectivas que, en cada etapa de su jurisprudencia, la Corte ha privilegiado en torno al respeto y garantía de los derechos humanos.

\footnotetext{
* Artículo 44 de la Constitución Política de la República de Guatemala: "Derechos inherentes a la persona humana. Los derechos y garantías que otorga la Constitución no excluyen otros que, aunque no figuren expresamente en ella, son inherentes a la persona humana. Serán nulas ipso jure las leyes y las disposiciones gubernativas o de cualquier otro orden que disminuyan, restrinjan o tergiversen los derechos que la Constitución garantiza".

** Artículo 46 de la Constitución Política de la República de Guatemala: Preeminencia del Derecho Internacional. Se establece el principio general de que en materia de derechos humanos, los tratados y convenciones aceptados y ratificados por Guatemala, tienen preeminencia sobre el derecho interno.
} 
b) Constitución y derecho internacional: ¿una relación jerárquica?

El contenido y alcances del artículo 46 constitucional fue materia de temprana interpretación por parte de la Corte de Constitucionalidad. En efecto, habiéndose instalado el tribunal en 1986, ya en 1989 debió pronunciarse al respecto, aunque en esa primera ocasión lo hizo sin mencionar expresamente el precepto.

Fue así como en 1989 el Congreso de la República en una -por demás inusual-solicitud de opinión consultiva, requirió a la Corte que se pronunciara sobre la situación en que se encontraban dos personas, posibles candidatos a la Presidencia de la República -cuya elección debía realizarse al año siguiente, es decir, en 1990-, con relación a las prohibiciones que para optar a dicho cargo prevé la Constitución*. Así, el Organismo Legislativo consultó si tales personas estaban impedidas de postularse en virtud de las prohibicio-

\footnotetext{
* La solicitud de opinión giró en torno a la situación de un militar retirado, quien a consecuencia de un golpe de Estado había asumido la Jefatura de Gobierno en la década de 1980, y la esposa del entonces Presidente de la República.
}

nes que el artículo 186 constitucional, incisos a) y c) ${ }^{*}$ respectivamente, establece ${ }^{* * .}$

Así, la Corte emitió su opinión el 16 de noviembre de 1989 (expediente 212-89), y en un escaso párrafo, sin mencionar expresamente al artículo 46, se refirió a la "recepción" de "otras normas" distintas a la Constitución, con especial referencia a las "de derechos humanos", y su relación con esta última, elemento que, a la postre, conforman el contenido y alcances del referido artículo 46. En tal sentido, la Corte consideró que la "recepción" en el derecho interno de esas "otras normas", sin importar "que pertenezcan al catálogo de derechos humanos", se torna inadmisible si resultan "contrarias al espíritu y aún menos al tenor expreso de la Constitución", pues esta última "se encuentra por encima del Derecho interno en cualquiera de sus formas".

\footnotetext{
* Artículo 186 de la Constitución Política de la República de Guatemala: "Prohibiciones para optar a los cargos de Presidente o Vicepresidente de la República. No podrán optar al cargo de Presidente o Vicepresidente de la República: a) El caudillo ni los jefes de un golpe de Estado, revolución armada o movimiento similar, que haya alterado el orden constitucional, ni quienes como consecuencia de tales hechos asuman la Jefatura de Gobierno; [...] c) Los parientes dentro del cuarto grado de consanguinidad y segundo de afinidad del Presidente o Vicepresidente de la República, cuando este último se encuentre ejerciendo la Presidencia, y los de las personas a que se refiere el inciso primero de este artículo; [...]". El texto transcrito corresponde con el contenido original de la Constitución, el que no ha variado en cuanto a tales preceptos desde su promulgación en 1985.

** La solicitud de opinión motivó la promoción de un amparo, el que fue denegado con voto discrepante de uno de los magistrados, quien entendió que la materia no era propia de una consulta, en tanto se refería al ejercicio de los derechos de personas específicas. Cabe acotar que, muy probablemente, sería este el criterio que la jurisprudencia sostendría en la actualidad si una opinión similar fuera planteada
}

Volumen 4 | Número 2 | Julio-Diciembre 2021 
Cabría cuestionar por qué la opinión incidió en el alcance del artículo 46 y, más aún, por qué la interpretación sostenida se encaminó a enfatizar el carácter superior, normativamente hablando, de la Constitución. La respuesta a tales interrogantes tiene que ver con el planteamiento de amparo que un año después se efectuaría, para cuya resolución la Corte, esta vez expresamente, dejaría sentado su criterio interpretativo en torno al precepto en referencia.

Pues bien, en 1990, ante la negativa del Tribunal Supremo Electoral, con fundamento en el inciso a) del artículo 186 constitucional, de inscribir la candidatura presidencial de una de las personas cuya situación política había sido motivo de la opinión consultiva del año anterior, los partidos políticos que respaldaban la candidatura promovieron la correspondiente acción de amparo. Dentro de los argumentos expresados, los accionantes señalaron que la prohibición del artículo 186, inciso a), de la Constitución no podría tener aplicabilidad frente al artículo 23 de la Convención Americana sobre Derechos Humanos* ([CADH]. 22 de noviembre de 1969), cuyo texto no incluye limitaciones

* Artículo 23 de la Convención Americana sobre Derechos Humanos: "Derechos Políticos. 1. Todos los ciudadanos deben gozar de los siguientes derechos y oportunidades: a) de participar en la dirección de los asuntos públicos, directamente o por medio de representantes libremente elegidos; b) de votar y ser elegidos en elecciones periódicas auténticas, realizadas por sufragio universal e igual y por voto secreto que garantice la libre expresión de la voluntad de los electores, y c) de tener acceso, en condiciones generales de igualdad, a las funciones públicas de su país. 2. La ley puede reglamentar el ejercicio de los derechos y oportunidades a que se refiere el inciso anterior, exclusivamente por razones de edad, nacionalidad, residencia, idioma, instrucción, capacidad civil o mental, o condena, por juez competente, en proceso penal." para optar a la candidatura, dada la preeminencia que las convenciones sobre derechos humanos, al tenor del artículo 46 de la Constitución, tendrían sobre el derecho interno. En síntesis, el argumento pretendía contraponer a la Constitución (artículo 186, inciso a) frente a la CADH (artículo 23), dando preeminencia a esta última por virtud, precisamente, del contenido de la misma Constitución (artículo 46).

De esa cuenta, la Corte, mediante sentencia de 19 de octubre de 1990 (expediente 21290), denegó el amparo solicitado y, para el efecto, se explayó en la interpretación que, a su entender, derivaba a partir del citado artículo 46 a fin de "definir su posición al respecto" (como expresamente se indicó en el fallo). Así, el tribunal inició afirmado que la "supremacía" que la Constitución otorga a los instrumentos internacionales sobre derechos humanos respecto del derecho interno tiene relación con el reconocimiento a la "evolución" que "se ha dado y tiene que ir dando" en esta materia como lo expresa (España Vidal 2020). Hasta este punto, aunque el argumento permitiría una mayor explicación y podría haber obviado la perspectiva de supremacía, la interpretación iría en línea con una visión de optimización de los derechos humanos.

No obstante, a continuación, el fallo recondujo el análisis en términos de jerarquía normativa, obviando la finalidad esencial del contenido del artículo 46. De esa cuenta, la Corte señaló que "la jerarquización" de los instrumentos internacionales sobre derechos humanos permite su ingreso al sistema jurídico interno "con carácter de norma constitucional", siempre que "concuerde con [el] conjunto" de la Constitución, "nunca con potestad reformadora y menos derogatoria" de esta última.

\begin{tabular}{l|l|l} 
Volumen 4 & Número 2 & Julio - Diciembre 2021
\end{tabular} 
Si bien es claro que la interpretación correspondía con el texto del citado artículo 46, la propia sentencia señaló que el ingreso del derecho internacional se daría "no por vía" del precepto en mención, "sino por la del primer párrafo del artículo 44 constitucional", previamente citado en este trabajo. Tal alusión, que resulta difícilmente comprensible, dado que el artículo 44 no se refiere al derecho internacional, podría haber obedecido al objetivo de denotar que en el ámbito de los derechos humanos el documento o instrumento en el que estos encuentran reconocimiento y garantía no determina su grado de efectividad.

Sin embargo, el análisis del tema desde la perspectiva de la jerarquía normativa, y la referencia a potenciales conflictos entre la Constitución y esos otros instrumentos, distaría mucho de entender que, según el criterio sostenido por el tribunal, la efectividad de los derechos no residiría en la "jerarquía" del documento que los proclama.

Para terminar, la sentencia intentó respaldar toda la argumentación anterior añadiendo que, si los instrumentos internacionales en materia de derechos humanos "entraren en contradicción" con la Constitución, su efecto sería "modificado o derogatorio" de esta, lo que negaría la "rigidez y superioridad" que le son inherentes.

En definitiva, el criterio explicado, cuyos alcances definirían los parámetros de recepción del derecho internacional de los derechos humanos por más de dos décadas en Guatemala, se limitó a analizar el tema desde el prisma -eminentemente formal- de la jerarquía normativa, en congruencia con la teoría kelseniana de la necesaria regularidad del ordenamiento jurídico (Kelsen, 2011, p. 254).
En otras palabras, la Corte no ahondó en el fin último que habría pretendido el constituyente al redactar el artículo 46. Tal omisión podría justificarse en el afán por dictar un fallo que no cuestionara, en lo mínimo, la autoridad y supremacía de la Constitución.

Sin embargo, la defensa del orden constitucional exige, más que sujetar los criterios de interpretación a la literalidad de un texto que se autodefine como supremo, atender a los fines del conjunto normativo y axiológico de la Constitución, sin dejar de advertir que esta no es sino un instrumento para reafirmar la posición central de la persona humana "como sujeto y fin del orden social", para exigir la protección que el Estado debe proveer a la "persona y a la familia", y para reiterar la necesidad de ejercer cualquier función del poder público a fin de garantizar al ser humano "el goce de sus derechos y de sus libertades" (preámbulo, artículos $1^{\circ}$ y 140 CPRG).

Cabe agregar que la decisión del tribunal brindó una respuesta en la medida de los argumentos de quienes reclamaron su intervención, en tanto estos, aunque aludieron a la tutela de los derechos políticos frente a una normativa que los limitaría, según su parecer, infundadamente, basaron su reclamo en términos de jerarquía normativa.

En todo caso, aunque excede del objeto de este estudio, habría hecho falta una argumentación distinta para respaldar el fundamento -que ciertamente lo tiene, incluso frente a la CADH- de la prohibición para optar a la presidencia contenida en el inciso a) del artículo 186 constitucional. Para ello, la argumentación no debió discurrir por el tema de la jerarquía de normas, sino en la proporcionalidad de la limitación al derecho de optar al cargo, analizando su idoneidad, necesidad y

Volumen 4 | Número 2| Julio-Diciembre 2021 
razonabilidad en sentido estricto (Carbonell, 2008, p. 10).

\section{c) El bloque de constitucionalidad: la reconciliación entre normas}

Casi 22 después, el 17 de julio de 2012 (expediente 1822-2011), la Corte volvió sobre el texto del artículo 46 constitucional y reinterpretó su contenido, variando sustancialmente su criterio, aunque de nueva cuenta no anunció expresamente la innovación interpretativa.

Una primera referencia obligada de la sentencia de 2012 es que la argumentación que reflejó el nuevo análisis desarrollado fue expresada "en clave" de derechos humanos, es decir, poniendo el énfasis de la interpretación del artículo 46 en el interés por garantizar la máxima efectividad de los derechos. Esta sola circunstancia derivó en un cambio de perspectiva que evidenció un criterio sustancialmente distinto, en tanto la Corte dejó de lado -omitiéndolo incluso- el problema de la jerarquía normativa, para centrar la discusión en la garantía de los derechos y libertades. En otras palabras, el fallo puso el interés en lo que podría catalogarse como la expansión de la Constitución dogmática.

Pues bien, la sentencia, para entender y explicar la nueva función que se reconocería al texto del artículo 46 constitucional recurrió al concepto francés del bloque de constitucionalidad: bloc de constitucionnalité (Favoreu, 1990, p. 45), en el sentido de integrar a dicho bloque, en armonía con la propia Constitución, "las normas y principios" del derecho internacional de los derechos humanos.
De esa cuenta, el fallo hizo uso del bloque de constitucionalidad a fin de emplearlo como "herramienta de recepción del derecho internacional" en el sistema jurídico interno, con lo que se lograría cumplir dos objetivos de especial relevancia, a saber: (i) garantizar la coherencia del derecho interno respecto de los compromisos y obligaciones internacionales asumidas por el Estado en materia de derechos humanos, y (ii) lograr la "complementación" de la Constitución y el resto del sistema jurídico nacional con las normas, principios y valores del derecho internacional de los derechos humanos, lo que indudablemente posibilita una más amplia y efectiva protección de la persona.

No está de más indicar que ambos objetivos, además de estar íntimamente relacionados, responden a principios sustanciales del derecho internacional: pacta sunt servada e imposibilidad de invocar el derecho interno para justificar el cumplimiento de los compromisos internacionales (Convención de Viena sobre el derecho de los tratados. Artículos 26 y 27. 23 de mayo de 1969).

A su vez, el cumplimiento de ambos objetivos permitió dar respuesta plena al problema que por años supuso el texto del artículo 46 constitucional. En tal sentido, en el análisis hermenéutico del precepto constitucional, la virtud de la sentencia de 2012 fue haber logrado sustituir el concepto de jerarquía por el de complementariedad, cambiando la noción de supremacía normativa por una perspectiva de coherencia, lo que supondría una "reconciliación" entre el derecho interno y el derecho internacional de los derechos humanos ante el dilema en que los colocó el criterio de 1990. 
Lo anterior tiene un claro efecto práctico, pues ante un eventual $-y$ aparente- conflicto entre las normas que conforman el bloque de constitucionalidad, la solución no estaría en privilegiar una norma superior, dado que no existe relación jerárquica entre estas; en cambio, la respuesta exigiría analizar cuál de las normas, por su contenido y alcances, redundaría en una mayor tutela y protección para la persona, a fin de aplicarla preferentemente en atención al principio pro persona, el que sirve como pauta interpretativa básica en materia de derechos humanos.

Por último, resta comentar que en la sentencia de 2012 la Corte se arrogó la facultad de determinar, caso por caso, el contenido del bloque, es decir, qué normas lo integran. En armonía con el fundamento del bloque: la garantía efectiva de los derechos, se tornaría dudoso deducir que la Corte tiene el monopolio de nutrir el bloque, pues ello conllevaría que la eventual protección de un determinado derecho o libertad, garantizado por el derecho internacional, exigiría siempre la intervención de la justicia constitucional.

Por el contrario, lo indicado en la sentencia debe entenderse en el sentido que la Corte, como intérprete último de la Constitución, lo será también del bloque de constitucionalidad, pero ello no impide, como ha sucedido en la práctica, que sean los jueces ordinarios quienes vayan dotando de contenido al bloque mediante sus decisiones.

Para concluir, cabe reiterar que el fallo logró dinamizar el contenido del artículo 46, en congruencia con lo que podría entenderse que era el fin buscado por el constituyente. En definitiva, la sentencia incorporó una evolución jurisprudencial que ha significado una expansión del catálogo de derechos y liber- tades: los que la Constitución reconoce, los que recoge el derecho internacional y los inherentes a la dignidad humana, permitiendo una tutela más amplia y efectiva de estos.

\section{Conclusión}

La interpretación constitucional configura una labor de suyo compleja, la que no puede limitarse a reafirmar el contenido literal de los preceptos que la Constitución recoge, sino que exige advertir, desde una perspectiva finalista, los alcances que tales preceptos proyectan, con miras a garantizar el respeto de la dignidad de la persona y su esfera de derechos y libertades, en congruencia con la razón de ser del Estado.

La interpretación definitiva y actual del sentido y alcances del artículo 46 constitucional, en tanto reconoce la preeminencia del derecho internacional de los derechos humanos sobre el derecho interno, ha exigido dejar de lado la concepción formalista de la jerarquía normativa para enfocar el tema desde la perspectiva de los derechos, lo que ha supuesto una evolución jurisprudencial de notable incidencia y relevancia en lo que atañe no sólo a la tutela de los derechos, sino más aún, a la concepción misma de la función de la Constitución y sus preceptos.

El bloque de constitucionalidad, concebido jurisprudencialmente como herramienta de recepción del derecho internacional de los derechos humanos en el plano nacional, ha permitido avizorar la necesidad de hacer coherente el sistema normativo interno con los estándares internacionales y, a la postre, ha determinado que la relación entre ambas órbitas normativas no es de jerarquía, sino de complementariedad, lo que ha hecho factible una expansión de los ámbitos de protección

Volumen 4 | Número 2| Julio-Diciembre 2021 
y tutela de la persona, de sus derechos y libertades.

\section{Referencias}

Bobbio, N. (1991) El tiempo de los derechos. Editorial Siste.

Carbonell, M. (2008) El principio de proporcionalidad y la interpretación constitucional. Ministerio de Justicia y Derechos Humanos del Ecuador. Disponible en: https:// biblioteca.cejamericas.org/bitstream/ handle/2015/1914/6PPIC.pdf?sequence $=1$ \&isAllowed $=y$.

Favoreu, L. (1990). El bloque de la constitucionalidad. Revista del Centro de Estudios Constitucionales (5), 45-68. Disponible en: https://dialnet.unirioja.es/servlet/articulo?codigo $=1049150$.

Helmke, G. y Ríos, J. (2010) Tribunales Constitucionales en América Latina. Suprema Corte de Justicia de la Nación. Disponible en: https://www.uv.mx/veracruz/sea/ files/2013/05/Tribunales-Constitucionales-en-America-Latina.pdf.

Kelsen, H. (2011) La garantía jurisdiccional de la Constitución. Anuario Iberoamericano de Justicia Constitucional (15), 249-300. Disponible en: https://dialnet.unirioja.es/ servlet/articulo?codigo $=3764308$.

Naranjo, V. (2003) Teoría constitucional e instituciones políticas. Editorial Temis.

\section{Sobre el autor}

Doctor en Derecho. Ex Letrado de la Corte Suprema de Justicia y de la Corte de Constitucionalidad, órgano este último en el que también fungió como Director Ejecutivo del Instituto de Justicia Constitucional. Ex Secretario de Política Criminal del Ministerio Público. Actualmente Abogado Senior en la Corte Interamericana de Derechos Humanos. Catedrático universitario. Autor de diversas publicaciones.

Copyright (c) (2021) Julio César Cordón Aguilar

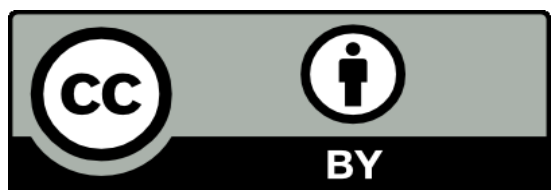

Este texto está protegido por una licencia Creative Commons 4.0.

Es libre para compartir, copiar y redistribuir el material en cualquier medio o formato y adaptar el documento, remezclar, transformar y crear a partir del material para cualquier propósito, incluso comercialmente, siempre que cumpla la condición de atribución: debe reconocer el crédito de una obra de manera adecuada, proporcionar un enlace a la licencia, e indicar si se han realizado cambios. Puede hacerlo en cualquier forma razonable, pero no de forma tal que sugiera que tiene el apoyo del licenciante o lo recibe por el uso que hace. 